\title{
O USO DA ESTÉTICA MANGÁ PARA REDESIGN DE CONTOS ALAGOANOS`
}

Mariana Petrovana Ferreira da Silva

Janaina Freitas Silva de Araúio

Amaro Xavier Braga Jr.

\begin{abstract}
Resumo: 0 objeto de estudo é a exposição: "As cinquenta histórias que minha avó contava”, ocorrente no Museu Théo Brandão, estado de Alagoas, durante o período de dezembro de 2014 até fevereiro de 2015, que trouxe histórias e cantigas tradicionais do interior alagoano como foco de sua narrativa. O presente trabalho visa apresentar como elementos oriundos do estilo de desenvolvimento japonês de histórias em quadrinhos - mangá - fora utilizado, para reconfigurar visualmente estas personagens que são fruto do patrimônio Imaterial do estado de Alagoas, e reapresenta-los ao público. Os contos de seres sobrenaturais que originalmente eram passados através da oralidade alcançaram a contemporaneidade, através de seu redesenho em formas reestruturados com o auxílio da narrativa cinematográfica característica dos quadrinhos japoneses. Considerou-se que várias formas de linguagem não estão necessariamente separadas, mas, sim, interconectadas (BARBIERI, 1998). Sendo assim, existe uma interligação na escolha do estilo mangá como aporte técnico para a transposição desses contos para ilustrações, visto que historicamente o Japão tem como um nicho de produção imagética justamente, contos que narram histórias de criaturas fantásticas. (LUYTEN, 2000). A estética mangá traz nas personagens traços simplificados e rostos expressivos (CHINEN, 2013), incorporada às criaturas e personagens que protagonizam as ilustrações da exposição. Um dos principais elementos trazidos do mangá para a releitura é o efeito Notan, com uso extenso de alto contraste entre preto e branco (BRAGA JR., 2011). Para além dos elementos exportados, algumas das obras que compuseram a exposição contaram com manipulação de cores terrosas e texturas que fazem alusão a paisagem do interior alagoano.
\end{abstract}

Palavras-chave: mangá; cultura; patrimônio imaterial, character design.

\section{POR QUUE MANGÁ?}

A proposta da exposição “As cinquenta histórias que minha avó contava” era, além de trazer à luz da contemporaneidade esses mitos e criaturas fantásticas do folclore local de Alagoas, fazê-lo a partir de uma estética cabível e apropriada à atualidade. O processo de criação da exposição deu-se conforme observação de prevalência de histórias infantis com narrativas à ocorrência de entidades fantasiosas, suas características peculiares, seu significado para os indivíduos responsáveis por sua propagação, sua importância na formação dos mitos regionais e o seu eminente desaparecimento diante de uma cultura contemporânea ainda mais habituada ao modernismo diante da performance e transformação do eterno.

1 Este artigo já foi apresentado na 3 Jornada Internacionais de Histórias em Quadrinhos (2015), com anais eletrônicos disponíveis em: http://www2.eca.usp.br/anais2ajornada/anais3asjornadas/artigos.php?artigo=artigo_080620152346052.pdf

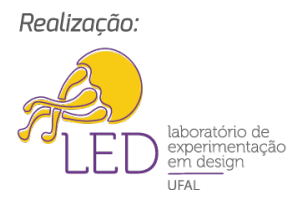


Dentre as muitas propostas estilísticas, a escolha dos elementos do quadrinho japonês mangá foi a que mais se encaixou com as necessidades do projeto. Os quadrinhos não são produzidos de forma igualitária; a forma como ele apresenta o uso de determinados elementos básicos, sendo estes mais empregados em alguns e menos em outros, proporcionando uma estética visual singular e específica a cada estilo; todos esses elementos mudam de acordo com o local onde ele é produzido. As nomenclaturas em cada país não devem ser tratadas como se fossem meras traduções do termo: "histórias em quadrinhos" (BRAGA JR, 2011), portanto, quando se faz referência ao termo mangá, o mesmo busca evocar a combinação dos elementos plásticos estéticos, uso de metáforas, ritmo de narrativa e onomatopeias que as histórias em quadrinhos feitas no Japão possuem.

Partindo do ponto de que mesmo sendo linguagens completamente distintas, tanto de sua base, uma sendo oral, e outra figurativa, e de culturas igualmente distintas, essas várias formas de linguagem não estão necessariamente separadas, mas se conectam em alguns aspectos (BARBIERI, 1998). As histórias em quadrinhos no Japão sempre souberam captar tendências de comportamento, decodificá-las e transformálas em sua linguagem característica (LUYTEN, 2000). Sendo assim, a apropriação desses elementos regionais e transposição deles para metáforas de linguagem como ocorre no mangá é uma das muitas referências que a exposição hibridiza para compor sua narrativa.

A escolha feita durante o projeto para a realização de uma adaptação além da construção de minimalistas traçados nipônicos partiu da ideia de "desconstruir e rearranjar" essas imagens tradicionais a fim de promover hibridização entre os elementos oriundos do mangá, proporcionando um character design² inovador das entidades e seres do folclore do interior alagoano. As obras expostas não devem ser consideradas tão simplesmente apenas meras mimeses do processo japonês, como obras sob alcunha de um mangá "nacional”.

As obras também incorporam em seu processo de composição conjunto de paleta de cores que remetem ao interior alagoano: principalmente nos tons de sépia, terracota e amarelo envelhecido, que recriam o contraste dos tons vibrantes com a imagem do interior, principalmente o aspecto de "envelhecido" ou "amarelado pelo tempo" que remete ao passado marcado por contos interioranos, oriundos de uma crença que ainda é subjugada pelos que vivem longe das fazendas, das grotas e dos campos de plantações de cana de açúcar, da mata atlântica alagoana e das ruínas dos antigos engenhos de escravos. As obras não deixam o espectador confuso quanto à apropriação do estilo mangá - ainda que este seja estrangeiro - sendo esta confusão amenizada pelo uso de uma paleta de cores terrosa e texturas.

Dentro do contexto, ao nos depararmos com o termo mangá nacional evocamos novamente aqueles elementos que se destacam em um mangá. No entanto, o termo nacional não se restringe somente à nacionalidade de quem produziu a história ou ao local de produção da mesma. A Quadrinista brasileira Awano (2005) que trabalhou durante muitos anos na produção de um mangá com título de nacional, esclarece três pontos de vista sobre o assunto, mas destaca um deles como mais importante:

Mangá brasileiro é um rótulo, uma etiqueta que define um tipo de produção que se utiliza de elementos dos quadrinhos japoneses para enriquecer o modo de fazer quadrinhos brasileiros. (AWANO, 2005, p.95).

2 Character Design, literalmente "conceito de personagem", é o termo usando mundialmente para identificar o modelo referencial de desenho para um personagem, que será consultado para a produção de outras ilustrações e produtos, que contenham o determinado personagem. 
Figura 1 - Procissão das Almas reúne trinta e seis entidades. A peça principal da exposição. Fonte: Janaína Araúio, 2015.

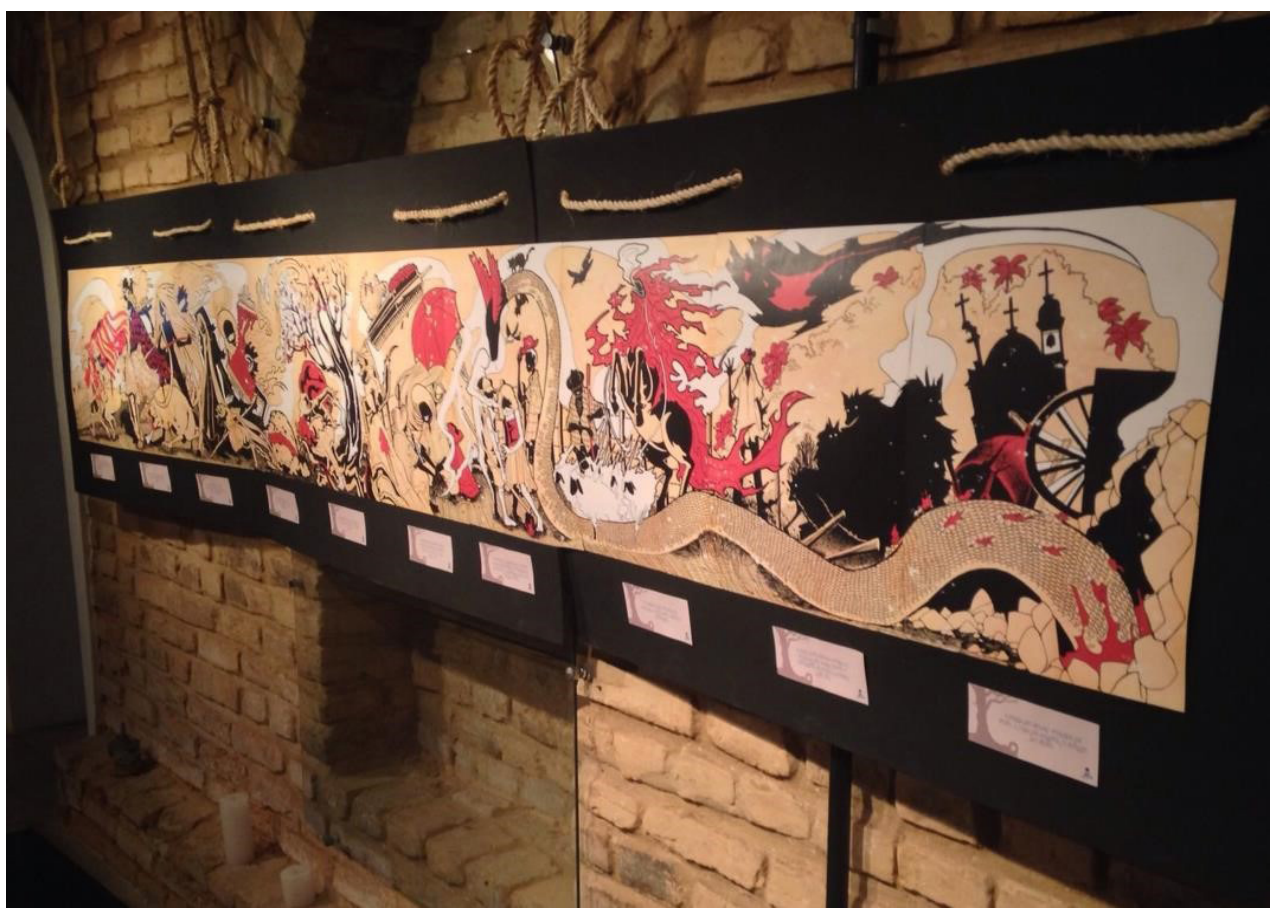

A exposição conta com dezesseis quadros que destacam oito entidades: Mulher da capa preta, Fogo corredor, Caboquinha, Cumade fulozinha, Correbixo, Lobisomem e 0 malassombro em cenas sequenciadas de encontros com o personagem protagonista (Miguel dos Santos), responsável pela narrativa dos fatos da história, apresenta os traços característicos do quadrinho japonês, rosto com expressões exageradas, traços anatômicos simplificados, e apelo carismático (CHINEN, 2013).

A peça central da exposição é uma grande obra, nomeada de Procissão das Almas. Ela conta com trinta e seis entidades retratadas. As entidades são representadas sendo guiadas pela luz do candeeiro de Miguel dos Santos e sua prima (Ana Maria).

Figura 2 - Caboquinha na Estrada. Uma das peças do primeiro corredor. Elaborado pelo autor.

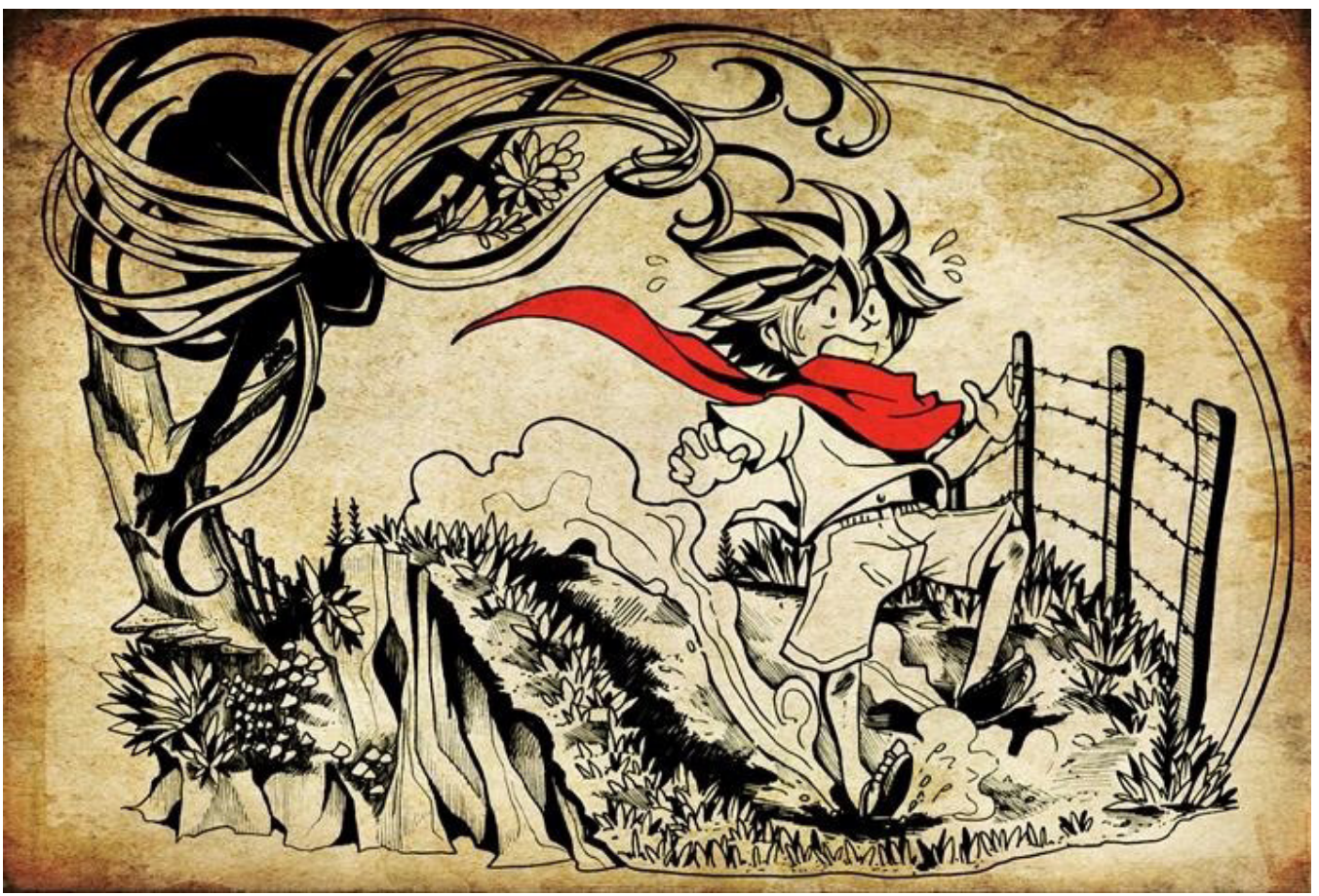


Além da narrativa expressiva fortemente cinematográfica com o uso da justaposição entre o personagem protagonista e a entidade retratada, as posições se alternam entre o primeiro plano, linha de frente, e o segundo plano, linha de fundo. Outra característica importada do estilo nipônico é o notan (BRAGA JR., 2011). Nesse estilo, o personagem protagonista e o antagonista formam um contraste através do uso de escuro e claro. 0 objetivo do emprego desse recurso é a facilitação para identificação dos personagens, assim como o emprego de impacto visual mais forte.

O efeito gráfico das obras não se limita somente às representações de algumas criaturas e dos personagens. Com o uso de tons de vermelho é possível categorizar as personagens. O vermelho mais vívido, mais saturado, representa seres que estão vivos de fato na trama, enquanto que o menos saturado serve para os seres sobrenaturais que se passam por vivos de acordo com as histórias.

O tom de amarelo terroso que provem da cor texturizada substitui o branco do fundo que, normalmente ocupa o material onde a imagem dos mangás é impressa; portanto, o tom de amarelo terroso forma o contraste com o preto das impressões. Na exposição, o emprego do branco assume outra função, aparecendo este mais fortemente na peça principal: Procissão das almas.

O tom de branco pode ser compreendido como passageiro e transitório. Seu maior apelo visual está na representação da fumaça que se esvai do candeeiro do personagem protagonista que guia a procissão; uma representação metafórica para a compreensão do leitor perante as histórias que eram contadas a luz do candeeiro nas casas do antigo interior de Alagoas.

As histórias eram repassadas sem nenhuma preocupação do registro formal, sendo relatadas oralmente. São, portanto, parte do patrimônio imaterial, consideradas como registros não formais de criaturas fantásticas de um folclore regional.

\section{MITOLOGIA BRASILEIRA? O FOLCLORE}

Partindo do pensamento que objetiva o enriquecimento dos quadrinhos nacionais, em específico o mangá nacional, a exposição se apropria também do uso da mitologia brasileira, especificamente o folclore regional, oriundo do interior alagoano, município de União dos Palmares.

As iniciativas brasileiras ainda são introvertidas no emprego de novos elementos hibridizados nos enredos. No entanto, algumas histórias ganharam notoriedade no mercado brasileiro. Os exemplos destes casos estão citados por algumas das histórias enveredaram pelo caminho do mangá brasileiro: Um certo Cézar Bravo Lubisome, história de Arthur Garcia e Silvio Spotti, lançados em Mangá Tropical (2003); e Madenka de Will WallBr, lançada na revista Ação Magazine (2011). 
Figura 3 - Pintura de Kitsune, em Ukio E (autor desconhecido) em comparação com Kuda Kitsune, do mangá XXX Holic, CLAMP (2003).

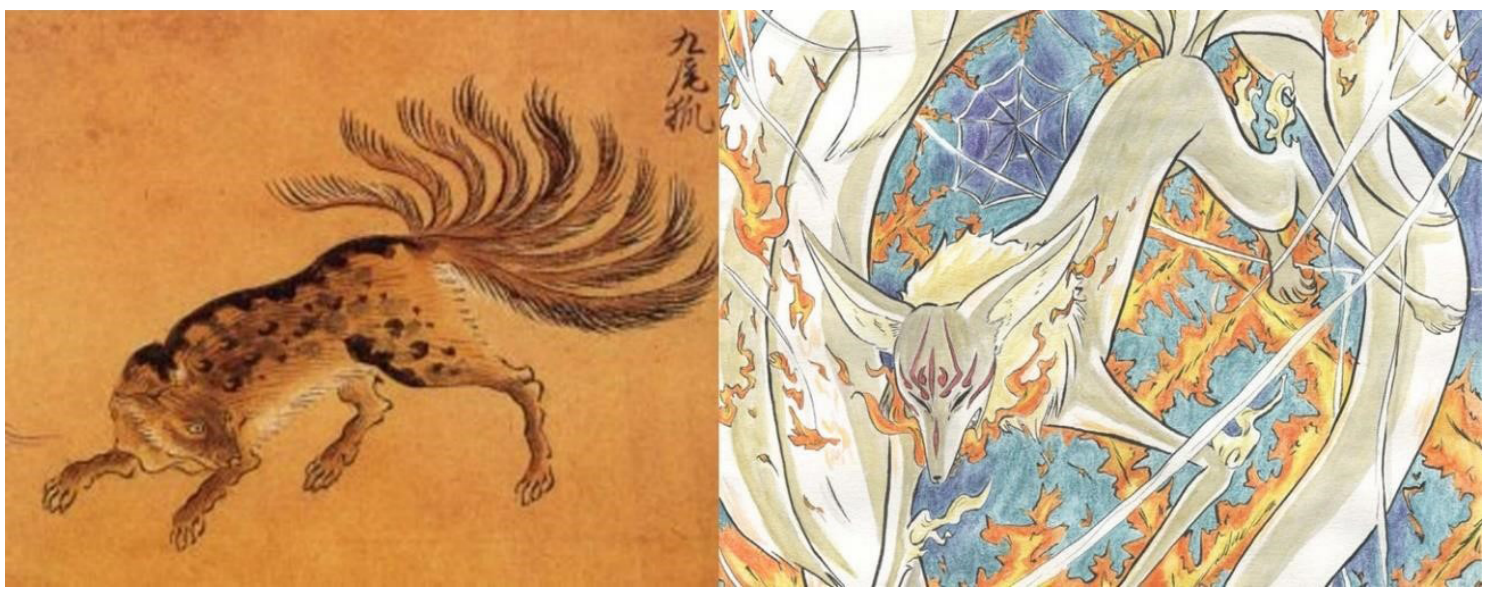

Da mesma forma que os japoneses fazem uso dos contos de seus youkais3, ayakashis, deuses e figuras lendárias para incrementar as tramas, o processo de criação da exposição não ocorreu diante de adaptação literal, mas de processo de transformação das figuras icônicas regionais para nova estética, mais fortemente pregnante. Essa transformação contempla o que é abordado por estudiosos da arte sequencial como mangá moderno.

Cachecol de Lã, um capítulo curto de autoria de Mariana Petrovana, ambientado no mesmo universo que a história da trama por trás das obras da exposição, foi exposto na $13^{\circ}$ Feira de HQ de Piauí.

O curto conto ambienta-se no município de União dos Palmares, interior alagoano, e narra a respeito de um mito local conhecido como 0 malassombro. 0 mito trata-se de uma interpretação da ideia de uma criatura fantástica, um fantasma. Essa mesma criatura é conhecida mundialmente, sendo abordada e apresentada de diversas formas em histórias em arte sequencial.

A Oneshot4 Cachecol de Lã serviu como obra piloto para o projeto da exposição. Através da sua combinação de elementos gráficos da estética mangá com um roteiro envolvendo contos regionais no decorrer de quatro páginas foi possível observar um esquema de cores e texturas para obtenção de um impacto visual diferenciado a fim de realçar o efeito sobrenatural da entidade de 0 malassombro.

No entanto, o processo de desconstrução das entidades ainda não havia sido desenvolvido. O desenvolvimento da ideia foi explorado posteriormente na composição da exposição: As cinquenta histórias que minha avó contava, na qual todas as criaturas eram facilmente perceptíveis como não-humanas. 
Figura 4 - Cachecol de Lã. História de capítulo único, exposta na 13 Feira de HQ’’s do Piauí. Elaborado pelo autor.

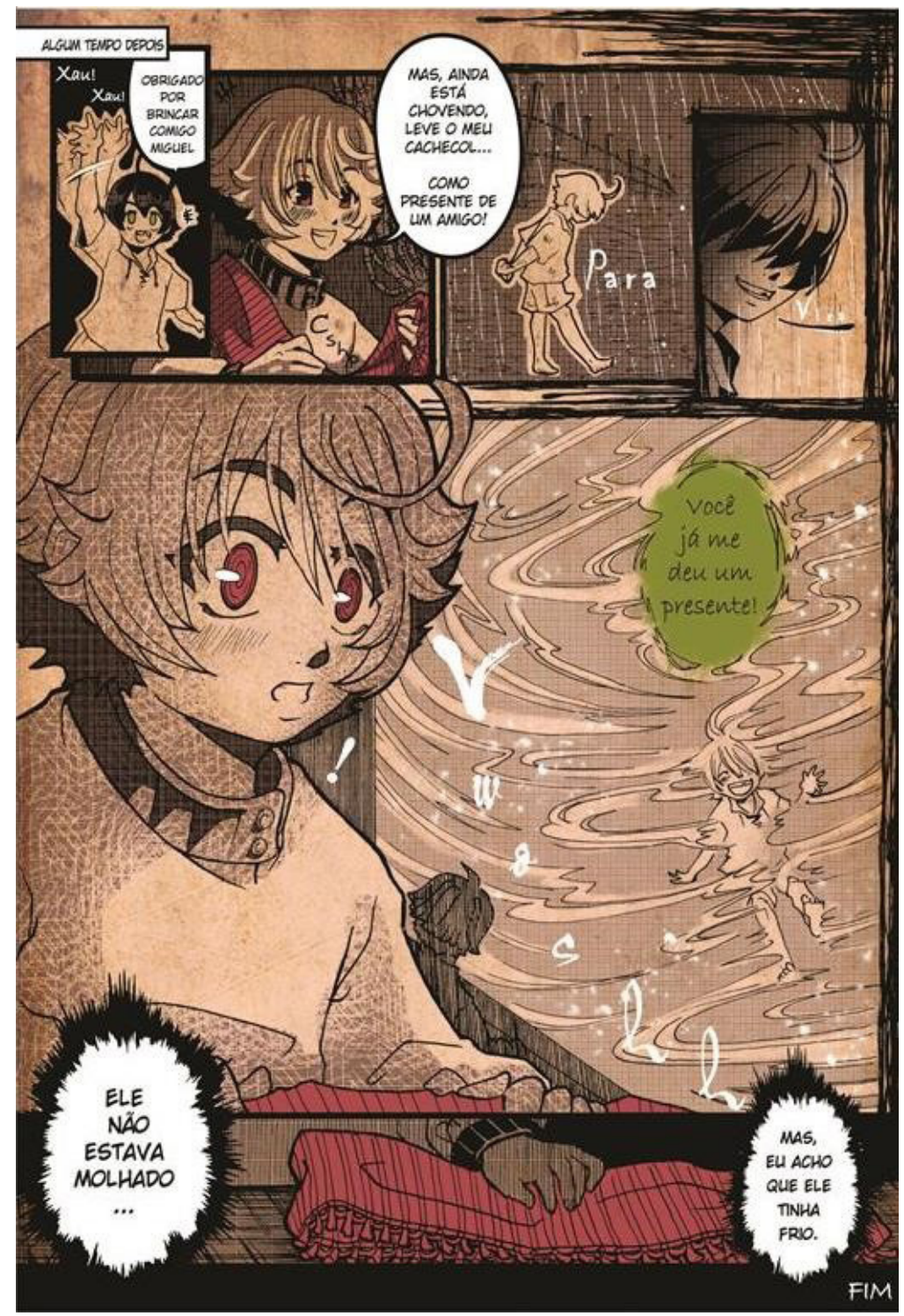

Dentro da perspectiva de desapego ao popularizado folclore nacional com seus personagens icônicos retratados de sul a norte brasileiro, desconsiderando-se as influências regionais e alterações, ainda que mínimas, nos contos fantásticos, esse projeto procurou proporcionar um mergulho nas raízes locais dos contos alagoanos, mais especificamente os de União dos Palmares, local onde a maior parte das histórias utilizadas foi recolhida.

O processo de adaptação da aparência das entidades partiu da descrição literal dos contos e cantigas para linguagem mais simplificada. Buscaram-se representações que fossem mais impactantes, porém, fáceis de se apreender em linhas objetivas, destacando apenas o que realmente seria necessário para reconhecer aquelas figuras sobrenaturais. 
Figura 5 - Fogo corredor. Rascunho de concepção do Character Design. Elaborado pelo autor, 2014.

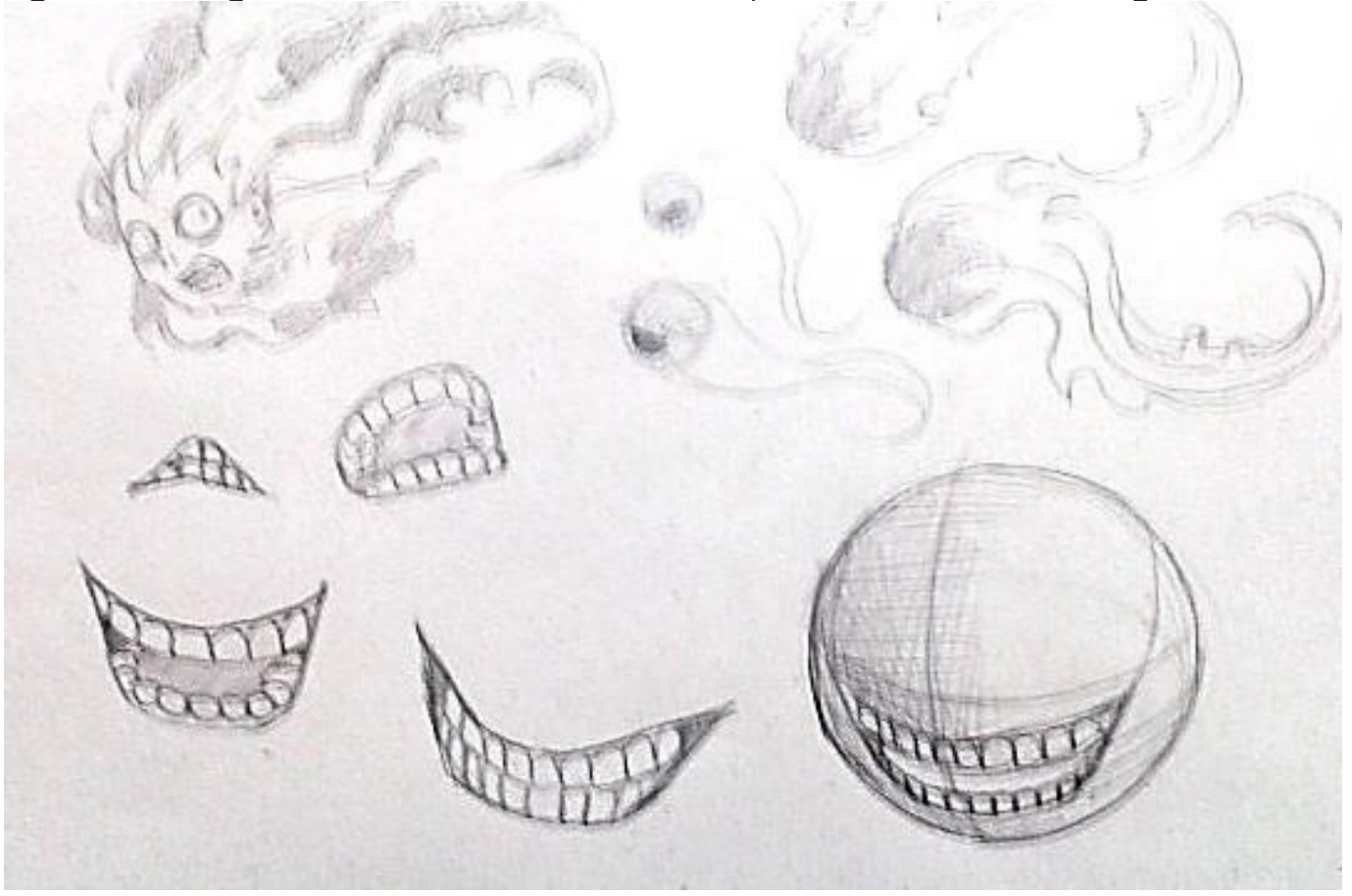

Quando um compadre e uma comadre se amigam, quando eles morrem suas cabeças não são comidas pela terra, e eles são amaldiçoados, as cabeças pegam fogo, e ele passam pelas estradas xingando um ao outro eternamente. Para quem ver de longe pensa que são duas tochas, de pessoas resmungando, mas ao chegar perto a pessoa curiosa tem um terrível fim. (Relato sobre o Fogo corredor, União dos Palmares, 2013).

O processo de adaptação com o Fogo corredor, por exemplo, seguiu a ideia em que as características mais fortes da criatura fantástica a serem representadas são: o fato de ser algo que flutua e está em chamas; e a necessidade por uma boca grande para reclamar. A ausência de olhos em todas as criaturas e entidades também faz parte do processo abstrativo que simplifica as imagens a fim de torna-las menos humanas e mais incógnitas. Cada uma das criaturas exigiu um trabalho de pesquisa e transposição de elementos principais pertinentes aos relatos encontrados com os moradores do interior de União dos Palmares. Essa adaptação permitiu que as criaturas fantásticas permanecessem reconhecíveis dentro dos parâmetros primordiais relacionados às histórias de sua respectiva origem. Todavia, foram adicionados elementos contemporâneos do mangá moderno para que a nova estética fosse agradável aos diversos públicos da exposição.

\section{CONCLUSÃO}

A exposição realizada durante o período de dezembro de 2014 a março de 2015 recebeu um público diversificado, desde visitantes locais, turistas e estudiosos da arte moderna, assim como pesquisadores de arte sequencial. A abordagem do conteúdo da exposição através da estética proporcionada pelos elementos gráficos presentes no mangá associado aos recursos anteriormente citados e exemplificados, possibilitou o acesso essa variedade de público. Crianças, jovens e adultos compuseram o quadro de visitantes do espaço disponível da exposição pelo Museu Théo Brandão, localizado na capital Maceió.

Vale ressaltar que para trabalhos que envolvem elementos culturais que já possuem uma prévia estrutura, o redesenho dessa formatação já conhecida acarreta em riscos. Afinal, o público alvo ainda precisa reconhecer aquelas entidades, elas não podem causar um estranhamento a nível de que se tornem irreconhecíveis. Por isso, cabe ao Design 
gráfico a tarefa de se utilizar dos levantamentos históricos, buscando os elementos necessários para fazer essa transposição de figuras, sem que nesse processo, o objeto se torne irreconhecível para o público alvo, e seja apenas fruto da interpretação pessoal do interlocutor.

\section{REFERÊNCIAS}

Livros:

AWANO, E. Mangá brasileiro. In: LUYTEN, S. M. B. Cultura pop japonesa. São Paulo: Hedra, 2005.

BARBIERI, D. apud RAMOS, P. A leitura dos quadrinhos. São Paulo: Contexto, 2009.

BRAGA JR., A. X. Desvendando o mangá nacional. Maceió: EDUFAL, 2011

CHINEN, N. Linguagem Mangá: Conceitos Básicos. São Paulo. Criativo. 2013.

LUYTEN,S. M. B. Mangá: o poder dos quadrinhos japoneses. 2 ed. São Paulo: Hedra, 2000.

Quadrinhos de Referencia:

GARCIA, Arthur, SPOTTI, Silvio e outros. Mangá Tropical. São Paulo: VIA LETTERA. 2003.

WALL, Will. Ação Magazine. São Paulo: Lancaster Editora, 2011.

Websites:

PETROVANA, Mariana. Cachecol de Lã, $13^{\circ}$ Feira de HQ’s do Piauí. Núcleo de Quadrinhos do Piauí. Disponível em: <http://www.youblisher.com/p/701514Trabalhosselecionados-da-13-Feira-HQ/>. Acessado em: 15 Out.

Sobre os autores:

Mariana Petrovana Ferreira da Silva (graduanda), UFAL <mariana.silva国fau.ufal.br> Janaina Freitas Silva de Araújo (graduanda), UFAL <Jana.f.araujo@gmail.com> Amaro Xavier Braga Jr. (doutor), UFAL <axbraga国gmail.com> 